\title{
Cotidiano da Educação Infantil: Espaço Acolhedor de Emancipação das Crianças
}

Rosa Batista ${ }^{1}$

É um grande privilégio ter sido convidada para participar deste fórum. É um evento importante porque provoca o debate e nos mobiliza para a construção da identidade da educação infantil; importante também, pelo lugar que ocupa na área e no cenário social e político em defesa de uma educação inclusiva, dos direitos sociais das crianças de $\mathrm{O}$ a 6 anos e de suas famílias.

A minha participação é no sentido de contribuir com o debate e com a construção de uma Pedagogia da Educação Infantil ${ }^{2}$ que privilegie as infâncias e não a alunância; que privilegie a diversidade e não a homogeneidade; que privilegie a espontaneidade ao invés do espontaneísmo; que estabeleça uma relação de complementaridade com as famílias e não de favor e caridade; que reconheça a criança com sujeito social de direitos e não mais como objeto de tutela; que a educação das crianças seja sinônima de emancipação ${ }^{3}$ e não de subalternidade.

Nesse sentido, a construção da identidade da educação infantil, passa pelo reconhecimento das crianças como sujeitos críticos e criativos, que criam jeitos próprios de interpretar e vivenciar as coisas do mundo, que produzem uma estética própria; são sujeitos que rompem com o estabelecido, mesmo que muitas vezes o façam na clandestinidade. As

\footnotetext{
${ }^{1}$ Professora da Universidade do Sul de Santa Catarina e pesquisadora vinculada ao Núcleo de Estudos de O a 6anos (NEEOA6) da UFSC.

${ }^{2}$ A expressão Pedagogia da Educação Infantil foi retirada da tese de Rocha (1999). No entanto, a autora esclarece que a utilização da terminologia Pedagogia da Educação Infantil visa a demarcação dos limites territoriais da educação de crianças pequenas em espaços institucionais coletivos, mas que nem por isso deve ser vista fora do campo da Pedagogia da Infância. E ainda: "Mesmo que uma Pedagogia da Infância se coloque apenas como uma possibilidade, uma vez que ainda não se encontra na realidade uma construção equivalente de orientações".

${ }^{3}$ Refiro-me à emancipação das crianças como a vivência de direitos sociais e políticos em contraposição à condição de tutela; de uma concepção educacional que tem como princípios as crianças como sujeito de direitos sociais e políticos que produz cultura. Falar de emancipação das crianças significa dizer que a educação infantil deve se tornar um lugar de emergência da infância, de vivência intensa e plena dessa fase da vida. Significa reconhecê-la como alguém que é e não como um vir-a-ser.
} 
crianças lutam pela emancipação quando se antecipam ao nosso movimento de outorga da condição de sujeitos de direitos, quando conseguem insurgir-se contra as regras e limites instituídas por práticas que ainda as consideram uns seres inacabados, frágeis, de "natureza corrupta e animal". "Sujeitos de pouca idade sim, mas que lutam através de seus desenhos, gestos, movimentos, histórias fantásticas, danças, imaginação, falas, brincadeiras, sorrisos, caretas, choros, apegos e desapegos, e outras tantas formas de ser e expressar-se pela emancipação de sua condição de silêncio","

Nós, professores, ainda temos dificuldade em compreender e legitimar as diferentes formas de as crianças viverem e atuarem no mundo. Suas práticas, marcadas pelas expressões das múltiplas linguagens, da simultaneidade, provisoriedade e pelo imprevisível, sempre foram tratadas como problema, cabendo à educação a tarefa de modificá-las, dominá-las no sentido do enquadramento social. Nessa perspectiva, educar tem como objetivo frear a imaginação, a fantasia, controlar o movimento, regular as múltiplas manifestações infantis, uniformizar suas temporalidades, desejos e sonhos. Talvez por isso os espaços e os tempos da educação infantil ainda revelem tanto a ordem, a estética, a previsibilidade, o controle da lógica adultocêntrica.

Pensar a educação infantil como espaço acolhedor de emancipação exige a recusa das práticas reguladoras, homogêneas, universalizantes e impessoais. Para tanto, faz-se necessário buscar nas crianças, nas suas práticas, nos seus modos de ser, a possibilidade da construção de novos tempos e espaços em que elas sejam respeitadas como crianças e possam viver como crianças. Não queremos uma educação que prepare para a emancipação, queremos que as crianças vivam a condição de sujeitos de direitos e principalmente o direito de aprender a ser criança e viver intensamente essa experiência.

Portanto, a emancipação das crianças, isto é, a vivência da condição de autor e ator social de direitos no espaço de educação coletiva, exige uma revisão das práticas que as submetem à condição de adulto em miniatura, de sujeito em maturação que um dia vai ser, de um ser frágil, incompleto, sem poder de escolha e de decisão sobre a vida vivida nas instituições; libertá-las de uma rotina homogênea, previsível, ordenada, assim como da temporalidade institucional onde todos têm que dormir, comer, fazer atividade, sentar na

\footnotetext{
${ }^{4}$ OLIVEIRA, A. M. R de. Entender o outro (...) Exige mais, quando o outro é uma criança: Reflexões em torno da Alteridade da Infância no Contexto da Educação Infantil. (Trabalho apresentado na 25 Reunião Anual da ANPEd, Caxambu MO, 2002).
} 
roda, ouvir a história, brincar no parque, ao mesmo tempo; libertá-las da lógica escolarizante, que insiste em ensinar de forma fragmentada "o mundo que já existe", que insiste em preparar para o futuro quando a experiência de ser criança está apenas começando a ser vivida. E, acima de tudo, desconstruir a idéia de que existe uma infância homogênea e universal.

\begin{abstract}
É preciso, portanto, repensar o foco do trabalho pedagógico nas instituições de educação infantil, que tem sido centrado muito mais na prática dos adultos do que nas práticas das crianças. Não estamos dizendo que um deva se sobrepor ao outro, mas sim que devemos incluir em nossas reflexões sobre a educação infantil um aspecto fundamental — os direitos das crianças de serem consultadas e ouvidas, de exercerem sua liberdade de expressão e opinião, e o direito de tomarem decisões em seu proveito. Outrossim, uma Pedagogia da Infância e, mais precisamente, uma Pedagogia da Educação infantil teria como um de seus princípios buscar a voz das crianças pequenas sobre a sua vida vivida nos contextos das instituições de educação infantil ${ }^{5}$.
\end{abstract}

Considero que a relevância desta reflexão consiste em "introduzir uma atitude crítica àquelas práticas que são dadas à nossa experiência presente como se fossem naturais, inquestionáveis e eternas"6. É preciso que nos incomodemos com as experiências vividas no cotidiano das instituições de educação infantil, principalmente aquelas cuja tendência é a de uniformizar, controlar, vigiar, conformar, ordenar, engessar o pensamento, a criatividade, a ousadia, a espontaneidade, a ludicidade que constituem as dimensões humanas. Precisamos desconfiar da harmonia, da homogeneidade, das práticas que pretendem o cultivo da docilidade e obediência, um cotidiano ordenado, controlável, previsível e impessoal.

Alguns estudos e reflexões que tenho realizado acerca do cotidiano da educação infantil, mais especificamente sobre a lógica organizacional do tempo e do espaço

\footnotetext{
${ }^{5}$ BATISTA, Rosa; CERISARA, Ana Beatriz; OlIVEIRA, Alessandra M. R. de.; RIVERO, Andréa S. Partilhando olhares sobre as crianças pequenas: reflexões sobre o estágio na educação infantil. Florianópolis SC, 2002. (mimeo).

${ }^{6}$ ROSE, Nikolas apud MOSS Peter. Reconceitualizando a infância: crianças, instituições e profissionais. In: MACHADO, M. L. A de. (org) São Paulo: Cortez, 2002, p. 237.
} 
predominante na organização da rotina da creche $^{7}$ têm evidenciado que a forma como o cotidiano dessa instituição está organizado dificulta a realização de um trabalho educacional pedagógico ${ }^{8}$ a partir dos princípios da emancipação, da pluralidade, da alteridade $^{9}$, dos direitos sociais, das culturas e manifestações próprias dos mundos infantis.

O que tenho observado nos encontros com profissionais ${ }^{10}$ de creches e pré-escolas ${ }^{11}$ é que há, de certa forma, uma naturalização da lógica organizacional da rotina. Nos cursos de formação com profisssionais da creche e pré-escola vai ficando mais visível a necessidade de urna discussão sobre a lógica de organização dessa rotina e suas implicações na vida das crianças e professores. Nas idas e vindas por várias cidades do Estado de Santa Catarina, trabalhando com as profissionais, tive oportunidade de constatar que a rotina não se diferenciava. Independente do lugar, a hora do sono, da alimentação, do parque, assim como as propostas de atividades, eram semelhantes. Numa ocasião, discutindo a organização da rotina da creche, uma professora perguntou: "O que é que a gente faz para mudar a lei da rotina? Onde que a gente tem que ir para mudá-la?”. Implícita à pergunta da professora estava a idéia de que a rotina é uma lei determinada por instâncias superiores e que deve ser colocada em prática em todas as creches, indistintamente. Outra professora dizia que em todas as creches em que ela havia trabalhado e todas que ela conhecia seguiam a mesma rotina:" É assim em todos os lugares e sempre foi assim".

\footnotetext{
${ }^{7}$ As reflexões tecidas neste trabalho são decorrentes e constitutivas do processo investigativo em nível de mestrado. Refiro-me à minha dissertação intitulada "A rotina da creche: entre o proposto e o vivido" (BATISTA, 1998).

${ }^{8} \mathrm{O}$ termo educacional-pedagógico está sendo utilizado no sentido dado por Maria Lucia de A. Machado (1996), para quem o atendimento institucional às crianças menores de 6 anos tem um caráter educacional no seu sentido amplo, mas tem, também, um caráter pedagógico, ou seja, de intencionalidade assumida, planejada, sistematizada pelos profissionais que desta tarefa participam.

${ }^{9}$ Refiro-me ao conceito de alteridade baseada no que diz Jorge Larrosa (1998:70) apud. OLIVEIRA: 2002: A alteridade da infância é algo muito mais radical: nada mais nada menos do que sua absoluta heterogeneidade no que diz respeito a nós e a nosso mundo, sua absoluta diferença. E se a presença enigmática da infância é a presença de algo radical e irredutivelmente outro, dever-se-á pensá-la a partir do que sempre nos escapa: à medida que inquieta o que sabemos (e a soberba da nossa vontade de saber), à medida que suspende o que sabemos (e a arrogância de nossa vontade de poder) e à medida que coloca em questionamento os lugares que construímos para ela.

${ }^{10}$ Utilizarei neste texto os termos profissional, professor e adultos para me referir a todos os profissionais que trabalham direta e indiretamente com as crianças nas instituições de educação infantil, (professores, profissionais da cozinha, da limpeza, auxiliar de sala e serviços gerais).

${ }^{11} \mathrm{O}$ termo creche neste texto faz referência ao atendimento institucional preferencial, mas não exclusivo à crianças de $\mathrm{O}$ a 6 anos e de período integral. O termo pré-escola é utilizado para o atendimento institucional às crianças de 3 a 6 anos em período parcial.
} 
Esta idéia de que a rotina é uma estrutura pré-definida ia ficando mais evidente à medida que em outros momentos e em outros lugares os professores de várias creches diziam coisas muitas vezes semelhantes ao falar da rotina. Todas as creches representadas pelas respectivas professoras tinham a mesma rotina. Essa semelhança era explicitada por elas da seguinte forma:

Nós não planejamos a rotina, porque ela não depende da gente. $O$ que sobra para nós é o planejamento da atividade pedagógica e, mesmo assim, temos um tempo determinado para fazê las. Os outros momentos do dia precisam ser seguidos de acordo com a rotina que já tem na creche, porque cada uma tem a hora de ir para o parque, a hora de ir para o refeitório, para dormir e para fazer a higiene. Se a gente não seguir este ritmo, a creche não funciona. É o caos na creche.

Este depoimento, como tantos outros, deixa marcas e revelam indícios de que a rotina parece ser uma estrutura que está além dos sujeitos que fazem parte do contexto da creche. Nas discussões nos diferentes grupos, tenho percebido junto aos profissionais as dificuldades de se insurgirem contra a organização do tempo e do espaço da creche materializados na rotina. $\mathrm{Na}$ fala de uma professora isso fica mais evidente:

O nosso tempo e o nosso espaço é definido pela rotina da creche. As vezes nós nem olhamos para as crianças para saber se o que elas estão fazendo é significativo ou não, se elas já terminaram de brincar se estão ou não com sono, se a atividade que a gente faz é interessante para elas. Nós olhamos para o relógio, se estiver na hora de dormir, por exemplo, temos que recolher todos os brinquedos e preparar a sala para dormir A mesma coisa acontece com a hora do almoço, da janta e do parque.

Percebo também que para os profissionais que atuam na creche, que estão dia após dia, semanas, meses e anos mergulhados na prática, vivendo e convivendo com as crianças pequenas, sob a determinação de uma rotina diária que lhes é tão familiar, torna-se difícil perceber os limites e as possibilidades que essa rotina possa ter. 
A pesquisa ${ }^{12}$ realizada mostra que tanto os profissionais quanto as crianças, quando chegam nessa instituição, encontram uma rotina diária que é comum a todos os grupos de crianças (hora de entrar na creche, hora de entrar na sala, hora do lanche, hora do parque, hora da higiene, hora do almoço, hora do descanso, e assim sucessivamente até o final do dia). O que se verificou é que as ações dos adultos, dos profissionais estão subordinadas a essa seqüenciação hierárquica, cabendo-lhes adequar os diferentes ritmos das crianças e os seus próprios ao ritmo único da rotina da instituição.

Assim, o tempo da creche parece não pertencer nem aos adultos e nem às crianças, mas a uma estrutura hierárquica regida por uma rede formalizada de normas em que o tempo objetivo e linear tenta se sobrepor ao tempo subjetivo dos sujeitos envolvidos no ato educativo, os adultos e as crianças. O tempo da creche parece estar alheio aos que nele atuam. Esses sujeitos, com funções distintas nesse contexto, parecem sofrer a opressão do tempo do relógio, regulado por forças outras que não eles próprios. No entanto, adultos e crianças sofrem diferentemente essa opressão. Enquanto os adultos têm a responsabilidade pela manutenção da rotina no cotidiano, as crianças têm o papel de vivê-la.

Do ponto de vista da lógica da rotina estabelecida, não é a atividade que determina o tempo, mas o tempo, que, de forma imperiosa, a determina. Cada atividade tem um tempo e um espaço definidos a priori para ser realizada no sentido da ordenação e seqüenciação prevista. Nesse sentido, não importa se a atividade está sendo significativa para as crianças, mas sim tentar manter a seqüência para garantir a pontualidade dos horários predeterminados. Assim, a fragmentação do trabalho pedagógico em unidades de tempo para cada atividade gera um processo de descontinuidade do processo pedagógico, uma vez que cada atividade é sempre interrompida pela próxima, independente da intensidade com que ela esteja sendo vivida pelas crianças e pelos e pelos adultos.

As múltiplas vivências das crianças chocam-se com a proposta de uma vivência única, cuja uniformização e homogeneidade são critérios para a organização e manutenção da seqüenciação das atividades previstas na rotina. Desse modo, as ações e reações das crianças frente ao que lhes é proposto no dia-a-dia da creche indicam um descompasso de intencionalidades, sentidos, desejos e necessidades que se manifestam em movimentos de ruptura, resistência e acomodação. Nesse sentido, a linearidade que caracteriza a rotina não

\footnotetext{
${ }^{12}$ BATISTA, op. cit.
} 
se materializa no cotidiano não-linear, em que a previsibilidade sucumbe ao imprevisível, ao inesperado, ao inusitado desse cotidiano. Portanto, a relação entre cotidiano e rotina é assimétrica. E não poderia deixar de ser, uma vez que as crianças são múltiplas, vivem experiências temporais diversas, porque seus tempos próprios não são instituídos, mas vividos, e, dependendo do contexto em que se encontram, conseguem vivê-los de forma mais ou menos intensa.

Os tempos e os espaços da creche estão organizados para vivências únicas (todas as crianças devem descansar ao mesmo tempo e no mesmo local, independente de estarem cansadas ou não; todas devem comer ao mesmo tempo; todas devem participar das atividades dirigidas ao mesmo tempo; todas devem ir para o parque ao mesmo tempo; etc.). Todas as crianças ao mesmo tempo e no mesmo espaço devem desenvolver uma única atividade de um mesmo jeito.

Todas devem começar e terminar ao mesmo tempo, assim como devem seguir os mesmos procedimentos para a realização das propostas feitas pelos adultos.

As crianças extrapolam essa unicidade, indo além do proposto. Fazem escolhas quando não deveriam fazer, optam por olhar o livro de história com gravuras, ao invés de ouvir o som da história que embala o sono que ainda não veio. Deitam, rolam, se acariciam no tapete, sem se incomodar com a hora do descanso, talvez porque não estejam tão cansadas ou nem um pouco cansadas.

Mesmo que se atribuam atividades padronizadas a todas as crianças com base em uma rotina que tem como certa a previsibilidade dos acontecimentos, em que se julga ser possível prever o próximo ato, não se consegue evitar a imprevisibilidade constituída na dinâmica do cotidiano plural, no qual se entrecruzam diferentes concepções de mundo carregadas de sentidos e significados construídos no contexto social e cultural do qual as crianças fazem parte.

Vai se evidenciando, assim, que a dinâmica do cotidiano infantil não cabe dentro de uma temporalidade estreita que desvincula o tempo de brincar e de trabalho, como também os tempos sociais, culturais, biológicos em função de um tempo padronizado e homogêneo.

As crianças vivem temporalidades distintas (não com a intensidade merecida), mas nem sempre são percebidas, pois muitas vezes são ocultadas por detrás de práticas rotineiras e naturalizadas que vão se cristalizando no dia-a-dia "como sendo assim mesmo". 
Ao apreender a estrutura hierarquizada, uniforme e homogeneizadora da rotina, a rigidez e a fragmentação dos tempos e dos espaços pré-fixados de atuação, foi possível identificar sua estreita aproximação com a lógica da organização temporal e espacial da escola.

A dificuldade em relação à especificidade do trabalho realizado com as crianças pequenas que permanecem em tempo integral na creche ${ }^{13}$ faz com que os adultos que trabalham com essas crianças pautem-se ainda muito fortemente pelo modelo escolar.

A forma como é organizado o tempo-espaço educativo da creche demonstra que ele é compreendido e organizado para sujeitos-alunos e não para sujeitos-crianças. Nesse sentido, os adultos vivem uma grande batalha diariamente na creche, qual seja: trabalhar com sujeitos-crianças dentro de uma estrutura cuja lógica temporal e espacial está assentada no sujeito-aluno.

Os adultos, em muitos momentos ou na maioria deles, parecem estar en tre a cruz e a espada. Percebem, no contato diário com as crianças, que elas têm necessidades diferentes e ritmos diferentes. Mostram-se angustiados em não conseguir atender a essas diferenças, permitindo que as crianças possam vivenciá-las. No entanto, eles não têm muitas alternativas. Oscilam entre cumprir a tarefa, que é ordenar e impor para todas as crianças uma atividade na mesma hora e no mesmo lugar e, ao mesmo tempo, abrir espaço para deixar aparecerem as diferenças, as necessidades, as individualidades, a simultaneidade, a "desordem", a provisoriedade, a criatividade, as múltiplas linguagens que constituem os modos de viver das crianças. Se trabalharem na perspectiva de atender às diferenças, permitindo que as crianças possam optar, escolher e decidir entre uma atividade ou outra, entre um espaço ou outro, menos alternativas os adultos terão, pois seu papel está atrelado à rotina predeterminada, concebida sob medida para trabalhar com sujeitos alunos.

O que se percebe é que a prática cristalizada nas instituições, a de propor a todas as crianças uma única proposta para ser realizada no mesmo tempo e no mesmo lugar, não condiz com as diferentes formas de ser e viver das crianças no mundo.

A percepção das ações e reações das crianças diante do que é proposto pelo adulto contribui para compreender que suas práticas são constituídas pela simultaneidade de ações

\footnotetext{
${ }^{13}$ A maioria das crianças brasileiras que têm acesso à creche permanecem nessa instituição de dez a doze horas por dia, sessenta horas por semana, duzentos e quarenta horas por mês, duas mil e quatrocentas horas por ano, durante os primeiros anos de suas vidas.
} 
em que a participação corporal, gestual, cognitiva, motora, emocional, afetiva e individual se dão de forma indissociável. Desse modo, a lógica inerente à organização do tempo e do espaço da creche dificulta as vivências simultâneas e plurais constitutivas das crianças pequenas. Este é um dado que merece ser objeto de nossas reflexões, pois essas vivências são geradoras de tensão e conflito entre os adultos e entre estes e as crianças. A relação que se estabelece entre o proposto pelo adulto e o que de fato é vivido pelas crianças não é linear nem simétrica, mas permeadas pelo conflito e pela tensão entre esses sujeitos que vivem diferentes papéis com temporalidades distintas.

Dizer que essa relação é permeada pelo conflito e pela tensão não significa que se tenha como modelo uma relação pedagógica idealizada, na qual possa existir uma convivência pacífica e harmônica entre crianças e entre elas e os adultos, sujeitos históricos e culturais cujas ações e reações são marcadas pelo lugar social que ocupam no contexto educacional da creche. Ao contrário, reconhece-se que a tensão e o conflito têm um papel importante na vida das crianças e dos adultos, que partilham sentidos, significados, valores, tempos, espaços, experiências, entre outros. Esses conflitos e tensões que constituem o cotidiano da creche, no entanto, podem ser vistos como indicações dos diferentes modos de ser e viver das crianças pequenas e da necessidade de repensar a forma de trabalho e a organização temporal e espacial para elas.

O que se percebe é que os universos das crianças são constituídos pela imprevisibilidade, espontaneidade, aleatoriedade, ludicidade, imaginação, criatividade, fantasia, pluralidade, brincadeira de faz-de-conta, linguagem artística, gestual, corporal, musical, entre tantas outras. Esse universo, na maioria das vezes, é secundarizado em uma estrutura cuja lógica de organização é linear, fragmentada, burocrática, homogênea, impessoal.

Vai se evidenciando que essa lógica de organização do cotidiano educativo, semelhante à do modelo escolar tradicional, não comporta os sujeitos-crianças, que vivem intensamente suas experiências, descobertas; que exploram os sentidos, os significados, as cores, a água, a terra, o fogo; que desejam tocar, mexer, desmanchas o que já estava feito; que fazem e refazem muitas e muitas vezes a mesma coisa; que significam e resignificam o mundo à sua moda; que correm, pulam, andam, sobem, descem, escorregam, se escondem embaixo da mesa, das cadeiras, contam e recontam a mesma história, lêem escrevem, 
cantam, dançam, e pintam ao mesmo tempo; que choram, riem, se encantam, vivem diferentes papéis: de mãe, pai, avô, avó, médico, aviador, motorista, professor; que criam e recriam um mundo de fantasia e imaginação, pintam a realidade, desenham o mundo, brincam de faz-de-conta, transformam uma caixa de papelão num tesouro, uma árvore numa floresta, um pneu num carro, um cabo de vassoura num cavalo, um prato num disco voador, uma colher num instrumento sonoro, fazem do lençol uma cabana; que conversam sozinhas sem se importar com o mundo a volta delas, produzem e reproduzem nas brincadeiras suas culturas a partir das culturas dos adultos. As reflexões tecidas até aqui revelam que os profissionais vivem cotidianamente o dilema de respeitar e partilhar a individualidade, a heterogeneidade, a simultaneidade, os diferentes modos de ser criança ou de seguir a rotina estabelecida, cuja tendência é a uniformização, a homogeneidade, a rigidez, a impessoalidade. A questão não está em optar de forma simplista por um ou por outro. Se faço desse jeito e não de outro. Não se trata aqui de uma opção pessoal e individual, mas sim de preconizar novas formas de intervenção na educação infantil, diferenciadas do modelo de educação escolar e, conseqüentemente, com sentido educativo próprio ${ }^{14}$ Isso exige condições muito diferentes das que estão estabelecidas nas instituições de educação infantil hoje, tanto para os adultos quanto para as crianças. São fundamentais profundas mudanças nas condições de trabalho e na organização dos tempos e dos espaços das crianças e dos adultos no contexto educativo das creches.

Estamos diante de desafios que acredito serem mobilizadores de um processo de desnaturalização/desconstrução de um modelo de organização do cotidiano da educação infantil fundamentado na perspectiva da falta, da incompletude, da ausência de direitos, da fragilidade, da necessidade, da carência das crianças pequenas e de suas famílias, pois somos herdeiros de uma cultura que concebe a criança como um objeto de tutela que precisa ser guiado, conduzido, controlado, vigiado pelo adulto, sujeito mais experiente,

\footnotetext{
${ }^{14}$ A construção da identidade da educação infantil exige a delimitação da sua especificidade cujas práticas sociais são distintas das práticas domésticas, escolares e hospitalares, Segundo Rocha, (1999), "Enquanto a escola se coloca como espaço privilegiado para o domínio dos conhecimentos básicos, as instituições de educação infantil se põem, sobretudo, com fins de complementaridade à educação da família. Portanto, enquanto a escola tem como sujeito o aluno e como o objeto fundamental o ensino nas diferentes áreas através da aula; a creche e a pré-escola tem como objeto as relações educativas travadas no espaço de convívio coletivo que tem como sujeito a criança de $\mathrm{O}$ a 6 anos de idade (ou até o momento que entra na escola)".
} 
aquele a quem historicamente é conferido o papel de regulador dos modos como as crianças devem viver. Segundo Oliveira ${ }^{15}$

(..) não se pode dizer que a criança é melhor ou pior que o adulto, ou que
é menos experiente que este, pois ela pensa e experiência a vida de maneira
diferente do adulto. Segundo Paulo de Tarso C. Sans (1994:23), as
crianças pensam com sentimento, seguem seus instintos e desejos; já os
adultos, procuram sempre a lógica do pensamento e do seu comportamento.
Pode-se dizer ainda que, se algum adulto insistir em ver as crianças sob o
prisma do não acúmulo de experiências, vale lembrar que para Walter
Benjamin (1984) a experiência é a máscara do adulto, que, baseado no
absurdo e na brutalidade da vida, impede e desencoraja a ousadia do
experimentar o novo (BENJAMIN, 1984:23), enquanto que as crianças, em
seus processos de vivenciar a vida, agem, segundo este autor, pelo
principio de Goethe de que "Tudo seria perfeito, se pudéssemos fazer duas
vezes as mesmas coisas"(BENJAMIN, apud SANS,1994:20), ou seja, estão
sempre dispostas a novas tentativas.

O que se percebe, no cotidiano da educação infantil, é que existe ainda uma grande distância entre o que se pretende e o que se realiza, entre o que se quer fazer e o que se pode fazer. A implementação de uma proposta de caráter educacional-pedagógico que possibilite às crianças a vivência digna dos seus direitos e se contraponha ao caráter assistencialista, espontaneísta ou compensatório de educação exige, além da qualificação e vontade dos profissionais, o comprometimento político-pedagógico da instituição, das agências formadoras, dos governantes e dos pesquisadores, que contam hoje com um vasto campo de investigação ainda em aberto, principalmente no que diz respeito às criações e produções simbólicas das crianças.

Entendo que o espaço da educação infantil precisa ser um lugar de produção de conhecimentos sobre as crianças. Isso também coloca o professor no lugar de pesquisador, de sujeito que faz perguntas sobre os universos infantis.

Isto implica o reconhecimento do que as crianças têm a oferecer: suas capacidades expressivas, imaginativas e criativas. É preciso que estejamos abertos para o encontro com as crianças, mais precisamente com a alteridade delas, com o que é próprio e radical do ser das crianças. Para tanto, é preciso construir outros tempos/espaços de reflexão entre os profissionais envolvidos com a educação e cuidado das crianças. Eles precisam de tempos e espaços para olhar, refletir, produzir conhecimento, planejar um cotidiano provocador da

\footnotetext{
${ }^{15}$ OLIVEIRA, op.cit, p. 5.
} 
fantasia, da imaginação, da brincadeira, do movimento, da alegria, do aconchego, do colo, de experiências, de descobertas, da participação efetiva das crianças nas decisões e projetos. Nessa perspectiva, as instituições se constituem como lugar de produções e manifestações das culturas infantis e, portanto, como lugar de emancipação das crianças.

Para finalizar, gostaria de dizer que não podemos mais aceitar que a rotina estabelecida no cotidiano das creches e pré-escolas nos impeça de pensar, de criar, de imaginar tempos e espaços que sejam ricos culturalmente e que tenham como mola propulsora às vidas das crianças na sua plenitude. As crianças, em suas ações e reações diante do que lhes é proposto, podem nos indicar caminhos.

Elas manifestam todos os dias como gostariam de viver, revelam através das suas múltiplas linguagens seus desejos, seus sonhos, suas preferências, suas angústias, seus medos, seus apegos, suas alegrias. Dizem-nos que a vida na creche e pré-escola poderia ser mais criativa e menos repetitiva. Dizem-nos que as coisas podem ser outras quando fazem um mundo sob medida para elas (embora os adultos insistam em dizer que isso é transgressão ou falta de limite).

Dizem-nos que vida de criança é agitada mesmo, que não conseguem fazer uma coisa de cada vez. Dizem-nos que a melhor hora da rotina é as horas do parque. Talvez porque esse lugar reserve algumas surpresas, descobertas, mistérios — há sempre um bicho escondido em algum buraquinho, um pássaro que voa baixo, uma árvore na qual possam subir, um buraco para ser explorado, amigos e irmãos para encontrar, possibilidade de construir e desconstruir enredos, histórias e fantasias - entre tantas outras coisas que só um olhar sensível e atento e uma escuta apurada é capaz de capturar. Precisamos treinar nosso olhar, nossa escuta acerca dos mundos das crianças, suas teorias, suas singularidades e diversidades. Essa é uma atitude que pode contribuir para uma auto-reflexão sobre o que sabemos, o que aprendemos sobre as crianças nos processos de formação e, conseqüentemente, sobre nossas práticas pedagógicas. O que sabemos hoje é que pouco ou quase nada sabemos sobre os universos infantis. E esse é um pressuposto que nos faz desconfiar das nossas certezas e acreditar que precisamos "nos alfabetizar nas múltiplas linguagens através das quais as crianças se expressam, que aprendamos a escutar, registrar e representar as vozes, os movimentos das crianças"16.

\footnotetext{
${ }^{16}$ OLIVEIRA, op. cit.
} 
Se queremos construir a identidade da educação infantil como espaço de emancipação das crianças temos que nos orientar também por elas, que, a seu modo, subvertem a lógica do disciplinamento, do controle, da homogeneidade, da linearidade, da temporalidade fixada na rotina das instituições, que buscam incessantemente revelar o que nossos olhos já não conseguem ver. Pereira e Souza enfatizam que,

A criança contém em germe a experiência - essencial ao homem - do seu
desajustamento em relação ao mundo, enfim a experiência da sua não
soberania. A incapacidade infantil de não entender certas palavras e
manusear os objetos dando-lhes usos e significações ainda não fixados pela
cultura nos faz lembrar que tanto os objetos como as palavras estão no
mundo para ser permanentemente ressignificados por nossas ações.
Palavras e objetos, podem por serem criações humanas, não são fixos nem
imutáveis. A infância, portanto, pode ser vista alegoricamente como
elemento capaz de desencadear (ou reencantar) o mundo da razão
instrumental, trazendo à tona a crítica do progresso e da temporalidade do
século das luzes. Porém, mais do que tudo isso, a criança, na sua
fragilidade, aponta ao adulto verdades que ele já não consegue ouvir ou
enxergar(...)

É preciso afirmar aqui que não podemos falar de emancipação das crianças, dos seus direitos sociais, sem considerar que os profissionais também devem assim ser considerados. Estou me referindo às condições concretas de trabalho, de existência, dos salários, da formação profissional, da vida vivida diariamente com as crianças.

A construção de uma prática emancipatória na educação infantil passa pelo exercício da solidariedade, da tolerância, da participação, da ética, da estética, da afetividade, do cuidado, da complementaridade com as famílias. Essas dimensões humanas talvez hoje estejam ofuscadas pela rigidez da lógica da rotina, e mais uma vez é importante dizer que é necessário construir outros jeitos de viver nas instituições de educação infantil. Penso que é preciso desejar que esse lugar seja diferente; é preciso acreditar nas crianças como sujeitos que têm coisas para nos ensinar e que nós também lhes ensinamos; é preciso escolher entre uma educação que se propõe a viver desafios e aventuras com as crianças ou uma educação que se propõe a ensinar o óbvio, a viver as coisas devidamente ordenadas e

\footnotetext{
${ }^{17}$ SOUZA LEITE, Maria Isabel (org.) Infância e produção cultural. Campinas, SP: Papirus, 1998: p. 25-42., Solange Jobim; PEREIRA, Rita Mansa R. Infância, conhecimento e contemporaneidade. In: SONIA e LEITE, M. Isabel(org) Infância e produção cultural. Campinas, SP: Papiros. 998: 35-36.
} 
previsíveis, vivendo um dia muito parecido com o outro. Vale ressaltar, que nossas escolhas não significam acertos e certezas nem que o que escolhemos seja algo pra viver eterna e imediatamente. Mas é preciso ousar, transgredir os limites da subserviência e da subalternidade, práticas que fazem parte da história da educação infantil' e que ainda estão presentes no cotidiano das creches e pré-escolas. Uma prática emancipatória tem como princípio o reconhecimento da alteridade, o que é próprio e radical do ser das crianças; oferecer condições concretas de participação nas decisões que envolvem suas vidas; legitimar suas decisões, suas produções, suas manifestações culturais; a atitude de ouvi-las, de enxergá-las nas suas diferentes formas de atuar no mundo; a ampliação das culturas infantis; a complementaridade com as famílias.

\section{BIBLIOGRAFIAS}

BATISTA Rosa. A rotina no dia-a-dia da creche: entre o proposto e o vivido. Florianópolis, SC. Dissertação (Mestrado em Educação) Universidade Federal de Santa Catarina, 1998.

BATISTA, Rosa; CERISARA, Ana Beatriz; OLIVEIRA, Alessandra M. R. de.; RIVERO, Andréa S. Partilhando olhares sobre as crianças pequenas: reflexões sobre o estágio na educação infantil, Florianópolis-SC 2002. (mimeo).

FARIA, Ana L. G. de. Impressões Sobre as Creches no Norte da Itália: Bambini si Diventa. In: ROSEMBERO, Fúlvia e CAMPOS, Maria M. (org.) Creches e pré-escolas no hemisfério norte. SP: Cortez: Fundação Carlos Chagas, 1994: 210-227.

KRAMER, Sonia \& LEITE, Maria Isabel (org.) Infância e produção cultural. Campinas, SP: Papirus, 1998: 07-10.

KUHLMANN, Jr. Moysés. Infância e Educação Infantil: Uma abordagem histórica. Porto Alegre: Mediação, 1998.

MACHADO, Maria Lúcia de A. Educação Infantil e currículo: a especificidade do projeto educacional e pedagógico para creches e pré-escolas. São Paulo, 1996. (mimeo).

MOSS, Peter. Reconceitualizando a infância: crianças, instituições e profissionais. In: MACHADO, M. L. A de (org) Encontros e Desencontros em Educação Infantil. São Paulo: Cortez, 2002, p. 237.

OLIVEIRA, A.M.R. de. Entender o outro (...) exige mais, quando o outro é uma criança: reflexões em tomo da alteridade da infância no contexto da educação infantil. (Trabalho apresentado na 25 Reunião Anual da ANPEd, Caxambu MG, 2002. 
ROCHA, Eloisa Candal. A Pesquisa Em Educação Infantil No Brasil: trajetória recente e perspectivas de consolidação de uma pedagogia. Campinas, SP. Tese de Doutorado. Universidade Estadual de Campinas, 1999.

SOUZA, Solange Jobim e \& PEREIRA, Rita Mansa R. Infância, conhecimento e contemporaneidade. In: KRAMER, Sônia e LEITE, Maria Isabel (org.) Infância e produção cultural. Campinas, SP: Papirus, 1998: 35-36. 